\title{
CUSTOMER INVOLVEMENT AND PRODUCT CONFIGURATORS IN SMES OKP WITH THE DOMINANT VARIATION OF THE TOPOLOGY
}

\author{
UDC 004.451.6
}

\author{
Dejan Aleksić ${ }^{1}$, Dragan Janković ${ }^{2}$ \\ ${ }^{1}$ University of Niš, Faculty of Sciences and Mathematics, Republic of Serbia \\ ${ }^{2}$ University of Niš, Faculty of Electronic Engineering, Republic of Serbia
}

\begin{abstract}
This paper is concerned with the complexity of the configuration process in small-and medium-sized one-of-a-kind production (SMEs OKP) with the dominant variation of the topology from the aspect of the position of customer involvement decoupling point (CIDP), batch size and the complexity of the product configurations process. The issues of the level of the product adjustment to the customer, complexity of the product configuration process, the possibility for the client to be integrated in that early phase of the production and the way of using the data obtained in the product configuration process for generating the final product specification of the customised product in this type of production have been discussed. A special concern has been given to the product complexity paradox, i.e. a risk that a customer may decide not to purchase the product because of too many technical details they encounter while configuring the product, as well as an inevitable extension of the leading time induced by the position of CIDP in this type of production. The division of configurators in three interconnected parts is suggested as the solution for the aforementioned problems: the front-end, middleend and back-end configurator. The paper emphasises the establishment of the necessary communication channel between the customer, i.e. the front-end configurator and the seller, i.e. the middle end configurator in order to alleviate the effects of the product complexity paradox. A positive effect of the automatic download of the generated data from the front-end and middle-end configurators by the back-end configurator on the leading time reduction has been also discussed.
\end{abstract}

Key words: Product configurators, One-of-a-kind production, Customer involvement decoupling point.

Received January 17, 2017

Corresponding author: Dejan Aleksić

University of Niš, Faculty of Sciences and Mathematics, Višegradska 33, 18000 Niš, Republic of Serbia

E-mail: alexa@pmf.ni.ac.rs 


\section{INTRODUCTION}

\subsection{Overview}

Nowadays, market requirements and technological advancement have been experiencing increasing changes being exposed to an obvious competitiveness, which in turn influences the product development process. Mass production of identical products, which used to be a dominant model of industrial production in the past, is no longer practised in most of the modern industries which are now governed by an ever growing trend of transferring from the manufacturer-oriented to the customer-oriented product development [1]. Customers demand a product at a comparatively low price, of high quality and fast delivery, while simultaneously expecting that the product meet their individual needs and requirements. This inevitably means that a customer is to be included in the production process, since keeping customers happy is one of the key strategies a business should follow [2] and the top priority of any business.

\subsection{Customer involvement decoupling point (CIDP)}

The position of the customer involvement decoupling point (CIDP), the point at which the customer is being included in the production process, determines the degree of the product adaptability to the customer, i.e. the customer's prospective impact on the characteristics of the final product [3].

At the time of the craft manufacturing, the CIDP was placed at the very beginning of the production process, since products were manufactured upon the individual orders of each client, which meant that the customer was directly involved in the process of the product definition. Mass production was introduced with the purpose of reducing the production duration and expenses. The actual position of the CIDP in mass production is at the very end of the production process. Therefore, on the one hand, there are favourable conditions considering the aspect of production process organisation and effectiveness, whereas the level of satisfying specific needs of every individual customer is rather low, on the other. Mass customization (MC), which is to provide products and/or services adapted to the needs of every individual customer as effectively as a serial or mass production [4] has created the possibility for customers to be reintegrated in the production process. Mass customization may occur in different phases of the production process, from the simple adjustment up to the total adjustment [5]. One of the most frequent ones is the configuration design in which the CIDP position is moved backward and placed before the assembling process. The integral components are projected in advance and manufactured following the predictions so as to ensure the quick delivery and a great number of different product variants, since the assembly process has been postponed until the customer makes their final choice [6].

\subsection{One-Of-Kind Production}

It has become an obvious trend among the manufacturers to additionally shift the CIDP position to the earliest possible phase of the production cycle with the purpose of increasing the level of adjustment. The switch of the CIDP to the earlier phases of the production cycle is expected to bridge the gap between the actual customer requirements and what the manufacturer can provide, the product specifications, because the customer will thus be in the position to be included in the product creation in the earlier phases of 
the production cycle [7]. In some industries, this tendency generates a new production strategy known as One-Of-Kind Production (OKP). OKP is a new manufacturing approach with the purpose of providing customized products based on requirements from individual customers, while maintaining the quality and efficiency of the mass production [8]. Compared with the traditional mass production approach, where costs of production are reduced by eliminating the numbers of product variations, OKP can better satisfy the various requirements of individual customers [9]. In our research, we focus on the small-and medium-sized one-of-a-kind production companies (SMEs OKP). In middle-size OKP companies, the CIDP is shifted further backward up to the step of the product design, whereas in small OKP companies, the CIDP is switched to the step of procurement. Although the OKP has been considered a promising approach to meet today's market demands, it also faces many challenges due to the large variations of OKP products. Three types of product variations, configuration variations, parameter variations and topology variations, are considered in the modelling of OKP products and the identification of the optimal product based on customer requirements [10], [11].

\subsection{Product configurators}

It is the product configurators that may have a key role in lessening the detrimental effects of the product variety paradox [12]. A product configurator is a subtype of a software based on expert systems or knowledge-based systems whose crucial purpose is the transfer of every individual customer's needs into a complete and valid product specification that will satisfy the customer's needs within the production range of a company [13]. As regards OKP companies, the use of product configurators has created a number of benefits, such as shorter deadlines, higher product specification quality, preservation of knowledge, less financial burden for product specification, product optimisation, less routine work, improvement of delivery safety and shorter period of training new employees.

This paper considers the overall complexity of the configuration process in the OKP with the dominant topology product variation from the aspect of the CIDP position, batch size and complexity of product configurations (Fig. 1). Several important issues have been emphasised: the possibility of product adjustment in this type of production, the complexity of the product configuration process, an effective involvement of customers in such an early phase of the production cycle and the use of the data obtained in the product configuration process for generating the final product specification of the customised product.

Considering the position of the CIDP in the OKP, the customer is allowed to have a significant influence on the characteristics of the future product, but it is almost impossible to "hide" from the customer all the complexity of the adjusted product configuration process, especially in the OKP with the dominant topology product variation product complexity paradox. The use of traditional web configurators may bring only a partial solution, which means that the customer has to be informed about a lot of technical details so as to configure the product which will satisfy all their particular needs in a proper way. Besides the risk of the product variety paradox, there emerges the risk of the customer declining the purchase due to an excess of technical details for the product configuration and the complexity of the configuration process itself (product complexity paradox). 


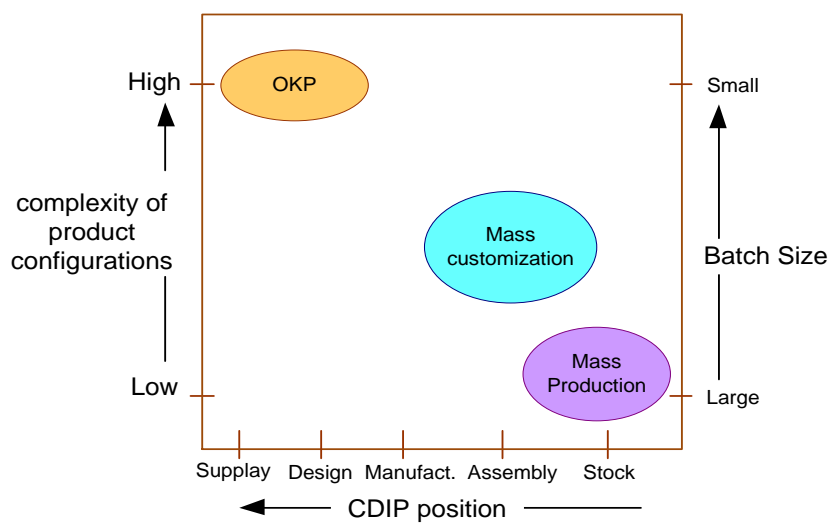

Fig. 1 Complexity of the product configuration, batch size and CIDP position in relation to different production strategies

Another consequence of the CIDP position is the extension of the leading time, which is quite expected since an earlier organisation of the production process is not possible because the final product specifications are not known in advance. The leading time may be shortened by an effective use of the product configuration data in forming the final product specifications and organising the production process of a particular product. This is particularly true when considering the fact that the batch size in the OKP is usually one or several and that a simultaneous production for different customers is quite a common and expected practice.

The problem of the configuration and production of adjusted products in the OKP with the dominant topology product variation may be resolved by dividing the configurators in three interconnected parts: the front-end, middle-end and back-end configurator. Customers initially encounter the front-end part of the configurator whose functions are similar to those of the configurators in the MC and which makes possible the adjustment of the products with the configuration and parameter variations. In case the configuration process is too complicated, e.g. the variation by topology is necessary or the knowledge of technical details is essential, then a new communication channel with a qualified person from the sales department is established, so that that person takes over the configuration of the desired product by using the middle-end configurator. One employee from the sales department can effectively "communicate" with a number of customers simultaneously, owing to the possibility that the middle-end configurator may automatically take over the data on the configuration process from the front-end configurator. The front-end configurator may display to the customer the results of the ongoing configuration process, which allows the customer to preserve their influence on the final product specifications and thus adjust them to their needs via an open communication channel with the sales department employee. The configuration process being completed, the middle-end configurator automatically generates the offer with the final product specifications and sends it to the customer. If the customer is satisfied with their offer, then they initiate the production of the adjusted product. In order to reduce the leading time, the production engineer generates the already configured data in the back-end configurator and proceeds with the configuration process, product specification preparation, product documentation preparation and frequently initiates the production of a particular product. 


\section{THE INFLUENCE OF CUSTOMERS ON PRODUCT DESIGN}

The analysis of the customer's influence on the production process defines four types of points at which the customer may exert influence on the production process: influence on the product design, i.e. design product family, demand for offer, i.e. customer inquiry decoupling point (CIDP), ordering a product, i.e. customer-order decoupling point (CODP) and customer view decoupling point (CVDP). The paper further analyses each of the aforementioned points in the contexts of the make-to-stok (MTS), assemble-to-order (ATO) and OKP production strategies.

\subsection{The influence of customers on the production process in the MTS productions}

Nowadays, the concept of the traditional production organisation refers primarily to the mass production - MTS. The main advantages of this type of production are the purchase of large amounts of raw material at retail prices and the production of as many standardised products as possible. Thus, the production process is organised most effectively and the amount of discarded material and waste is significantly decreased [4].

Customers' needs are taken into consideration following the results of various market polls and researches and they utterly depend upon the responsibility of designers and engineers to transfer the customers' wishes and needs into mutual demands and to adapt them to the future product specifications. The product design, purchase of resources organisation, production and assembly develop independently of an individual customer's wishes and intentions to possibly buy the product

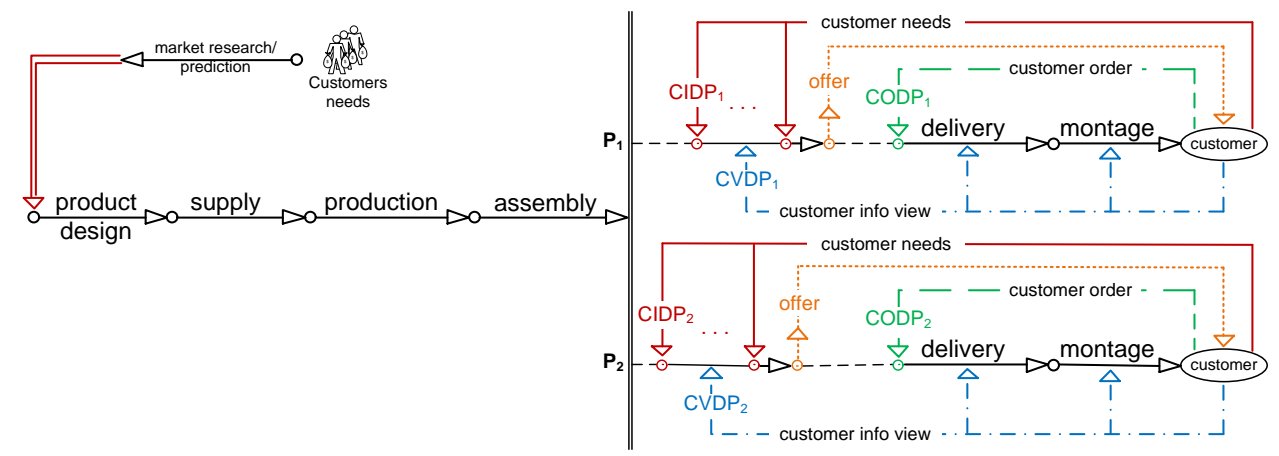

Fig. 2 Customer's influence on the production process in the MTS productions

Namely, the customer is integrated in the production process at its very final step (see the CIDP position in Fig. 2) by selecting those characteristics of the product which are most suitable to their needs, but the customer cannot directly influence the characteristics of the product they are buying. Since the products have already been manufactured and stored, their price is known and generating the offer for the selected products is then a very simple process. 


\subsection{The influence of the customer on the production process in the ATO production}

The prospects are that the companies applying the order production strategy, in the ATO and OKP, may manufacture a large number of possible variants of the future product. An excessive number of the future product characteristics, offered to the customer to choose from, inevitably produce the "bewildered customer" effect. One of the solutions to this problem might be the "product family" concept. Product families are designed so as to cover a particular part of the market, while each variant is developed so as to satisfy the individual needs of the customer in that segment of the market. The customer now chooses a particular product family and a product variant most suitable to their needs.

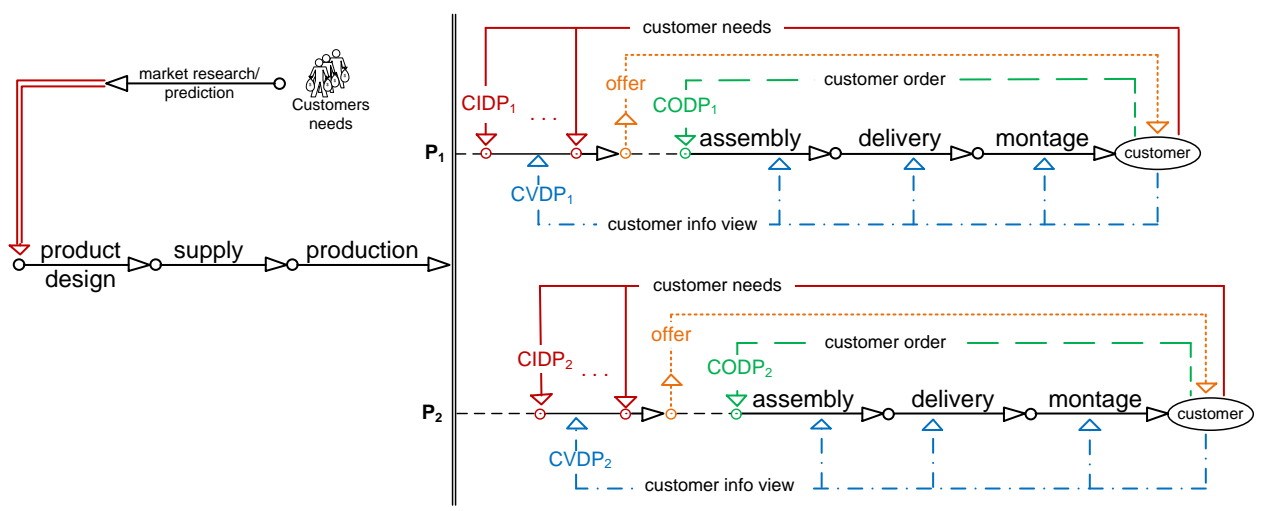

Fig. 3 Customer influence on the production process in the ATO productions

A direct influence of the customer in the ATO productions on the product characteristics and product families, as well, is similar to that in the MTS product strategies. This helps form the product families and product variants within them so that potential products possess as many mutual integral parts as possible. The supply of resources process and the integral parts production are thus optimised. Therefore, the resources supply and the integral parts production are carried out without any direct influence of the customer, i.e. the customer is actively integrated not before the assembly phase (CIDP points in Fig. 3). As it has been already mentioned, one of the solutions to the problem of the "bewildered customer" is the creation of the product families, while the other would be the introduction of the product configurators. Using the product configurators, the customer can convert their needs into the specifications of the product which is best suited to them [7]. Using the sales configurator, the customer, having defined the initial product specifications, automatically obtains a valid offer which contains the total price of the product and the predicted time of delivery (Fig. 4). If the customer agrees with the conditions of the sale, they order and pay for the selected product and thus initiate the process of the assembling of the product they configured (CODP point in Fig. 3). A great number of production systems allow customers to know exactly the phase of the production process in which their selected product is at any time (series of CVDP points in Fig. 3).

These configurators must make it possible for the customer to obtain the product which completely meets their needs but not without taking into consideration the manufacturing 
capacities of the company or the engineering constraints. The referential sources give a lot of examples on the application of configurators in the ATO productions.

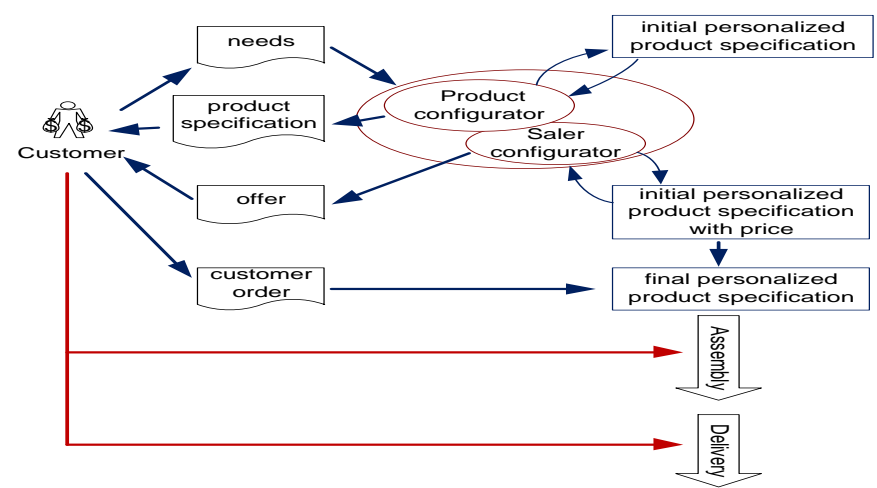

Fig. 4 Product configurator in the ATO production

\subsection{The influence of the customer on the production process in the OKP production}

This paper discusses the case of one middle size OKP company and one small OKP business that manufacture products upon the order of individual customers. The products are completely adjusted to the customers' needs, especially regarding their variations in configurations, parameters and topology. There is a wide range of materials used for manufacturing products in accordance with the needs of every individual customer.

Although the aforementioned productions manufacture basically the same type of products, these products differ mainly in their adjustment level and efficiency of the production process. Namely, a middle size OKP company is equipped with technologically advanced mass production assembly lines for manufacturing products adapted to the customers' needs, but it is because of the production process optimisation and the maximal utilisation of the machines that it has a somewhat lower level of product adjustment. Contrary to this, small OKP businesses, even though they are also equipped with technologically equally advanced machines, produce completely adjusted products with all possible variations in configuration, parameters and topology. The adjustment level is very high in this type of OKP production, but their production efficiency is smaller than in the middle size OKP companies.

Organisation of the purchase of materials represents another important difference. In middle size OKP companies, this purchase is done in accordance with the future production predictions and plans, which is similar to the ATO production, and is performed in advance so that raw materials are stored and always available to be used in the process of manufacturing at any time. This is essential because of a large volume of production of adjusted products and certainly, more favourable prices of raw materials. Middle size OKP companies frequently produce their own main raw materials. Small OKP companies purchase raw materials as custom drive supply, which means according to the demands of every individual customer. This is the consequence of the high level of production adjustment which necessarily requires a large number of various types of raw materials. Therefore, small amounts of different types of raw materials would have had to be stored in warehouses, which would make this type of production unprofitable. Thus, such OKP companies work with a well- 
organised network of suppliers and in that way deliver maximally adjusted products to every individual customer in due time. The extended delivery time is compensated with a higher level of production adjustment since any customer is willing to wait for the final product longer if it is completely adjusted to their personal needs.

In conclusion, in small OKP businesses, the delivery time is longer and the price is higher but the adjustment level is at its maximum, whereas in middle size OKP companies, the delivery time is shorter, the price is more acceptable but the adjustment level is lower.

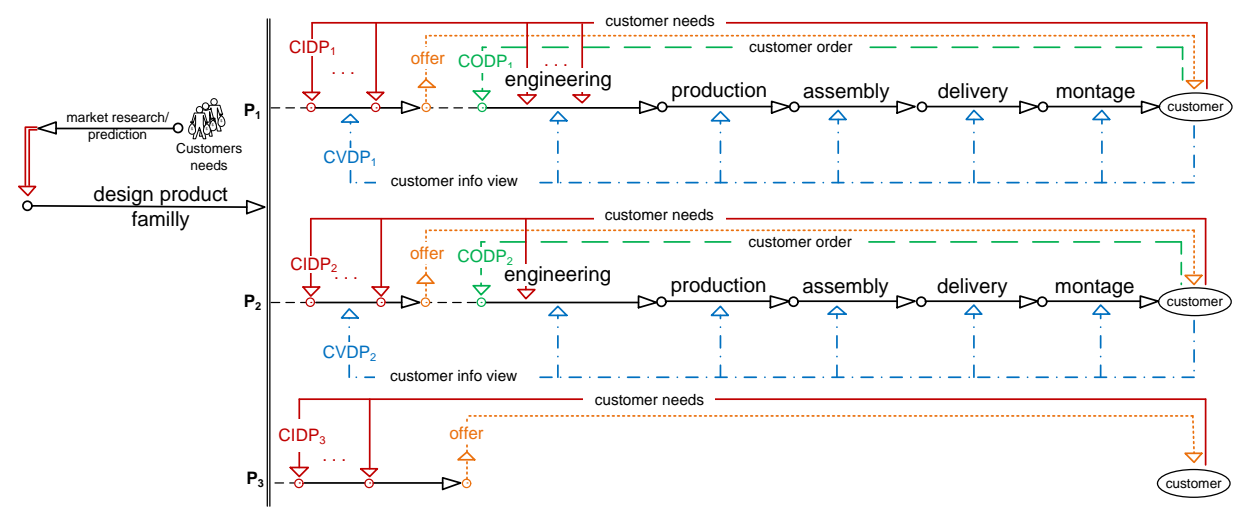

Fig. 5 Customer influence on the production process in the OKP production - general example

Similarly to the ATO production strategy, the products are here also divided into product families which facilitate the customer's choice of the product which is most suited to their individual needs. Hence, the analysis of the customers' general needs, manufacturing capability and engineering constraints initiates the creation of the product families which are considered to most likely agree with the potential buyers' needs. This instance represents the first point of customers' influence, though indirect, on the production process in one OKP company, which is similar to previously mentioned production strategies (Fig. 5).

Forming the product families means the beginning of the process of the product design. Unlike the ATO product strategy, in which a larger part of the final product design has been finished in this phase, the OKP product strategy performs only the initial future product design in this phase, while the final product design is done later after the individual customers' orders have been received [11]. After the creation of the product families, the OKP production is ready for the next phase of the production process.

The next phase, which is at the same time the first point of a direct customer's influence on the production process (CIDP point in Fig. 5), is the moment when the customer sends a demand for an offer so as to obtain complete information about all the conditions under which they can purchase a desired product. Important factors are the product price, delivery time and the adjustment level of the future product. This is also the moment when a particular product design is started following the initial demands of every individual customer. The customer is allowed to have an insight into the future product specifications (a series of CVDP points in Fig. 5) and to be actively integrated in the design process of the adjusted product (CIDP points in Fig. 5). 
Compared to the MTS and the ATO productions, process of creating offers in the OKP the situation is significantly more complex. The primary reason being the fact that not even initial product specifications have been known up to that point so that this phase may be regarded as the actual beginning of the adjusted product production. Considering the CIDP position, the customer is naturally given a possibility to exert a significant influence on the future product characteristics, but it is almost impossible to keep the customer in the dark about all the complexity of the adjusted product configuration, especially in the OKP with the dominant topology variation.

Several important issues are particularly conspicuous: the possible level of product adjustment by the customer in this type of production, the level of complexity of the product configuration process, the effective integration of the customer in this early phase of the production chain and the utilisation of the data obtained in the product configuration process for generating the end product specifications of the customised product.

The use of the traditional web configurators may only partially solve this problem, so that the customer has to be informed about lots of technical details in order to properly configure the product that will meet all their particular needs. Similarly to the aforementioned product variety paradox risk, here emerges the product complexity paradox (too many technical details the customer encounters during the product configuration) which may induce the customer to decline the purchase of the product due to the complicated configuration process. Another consequence that may arise is the extension of the leading time, which is quite expected because it is impossible to completely organise the production process in advance since not all specifications of the end product are yet known. The problem of adjusted products configuration and production in the SMEs OKP with the dominant topology product variation may be resolved by the division of configurators into three interconnected parts: the front-end, middle-end and back-end configurator (Fig. 6.

It is thus possible to shorten the leading time by a more effective use of the data from the configuration process during the creation of the final product specifications and production process organisation of that particular product. This is particularly true when considering the fact that the batch size in the OKP usually equals one or several and that the simultaneous production for different customers is a rather common occurrence.

In case the configuration process becomes too complex, e.g. if the topology product variation is also necessary or the knowledge of technical details is required, then a new communication channel is established with a trained and qualified employee from the sales department who continues further the product configuration. It is of an utmost importance to emphasise that the customer is still allowed to influence the end product specifications and thus adjust the product to their needs via an open communication channel with the sales department employee. The configuration process completed, the configurator automatically generates the offer with the final product specifications and sends it to the customer who replies to it after some time. Hence, if the customer is satisfied with the offer, the customer places an order and thus initiates the adjusted product production, which represents the next direct point of the customer's impact on the production process in the OKP production, the customer order decoupling point, CODP (Fig. 5). The production process may end in this phase if the customer declines the already prepared offer (case $\mathrm{P}_{3}$ on Fig. 5). 


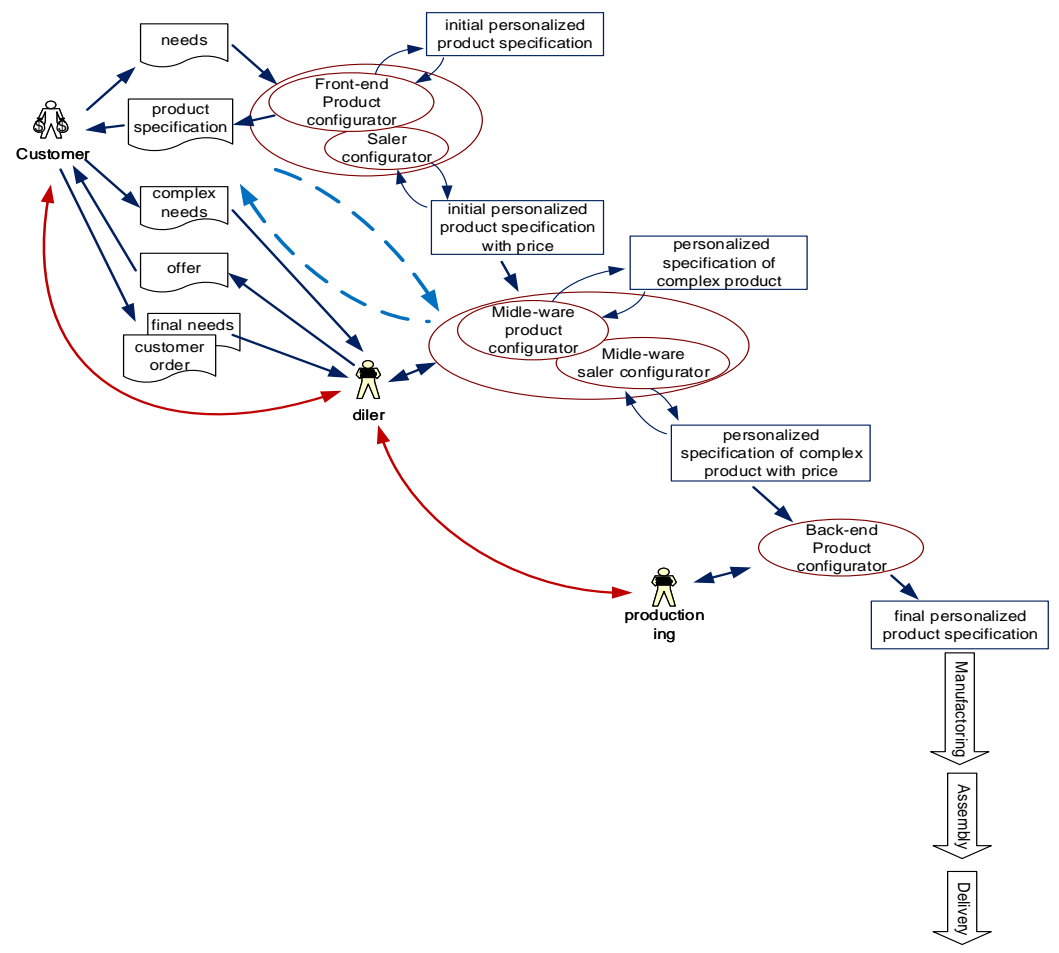

Fig. 6 Three different configurators in the OKP production

In order to reduce the leading time, the sales department engineer assumes the already generated configuration data in the back-end configurator and carries on with the configuration process, often called the post-configuration, prepares the production specifications of the product and the product documentation and frequently launches the production of the particular product.

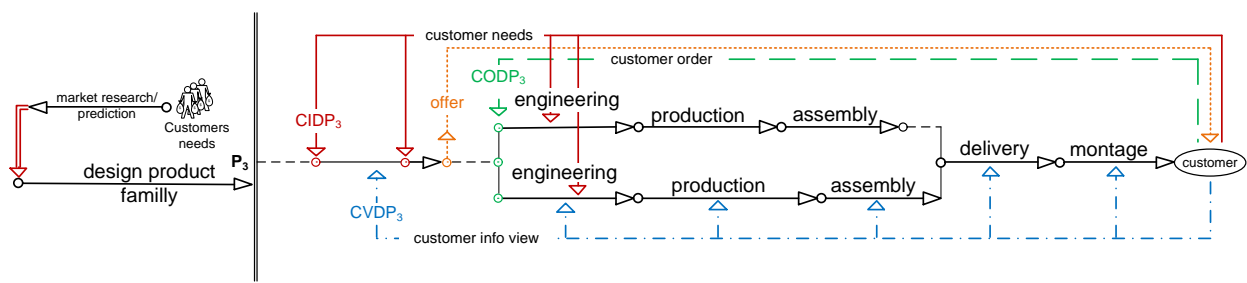

Fig. 7 Customer influence on the production process in the OKP production - large order case

It has been already mentioned that the OKP companies which manufacture products upon the demands of every individual customer base their production on technologically advanced machines. The majority of those machines can manufacture a limited number of products. This means that big orders will have to be divided into several work orders (see Fig. 7), while the back-end configurator is expected to support the automatic division of products into work orders in the most efficient way. 
Therefore, the post-configuration, i.e. engineering, production and montage of the products from the same order will be carried out simultaneously through several separate work orders so that, all the products finished, the mutual delivery and montage may be performed. The level of simultaneity depends primarily on the number of manufacturing lines the company possesses, as well as on the priority of the work orders that have been already launched into production.

An order containing a considerably small number of products constitutes a completely opposite, but rather frequent case. Their separate launching into production is not acceptable considering the utilisation level of production capacity and materials, so that only post-configuration, i.e. engineering, is performed simultaneously (Fig. 8).

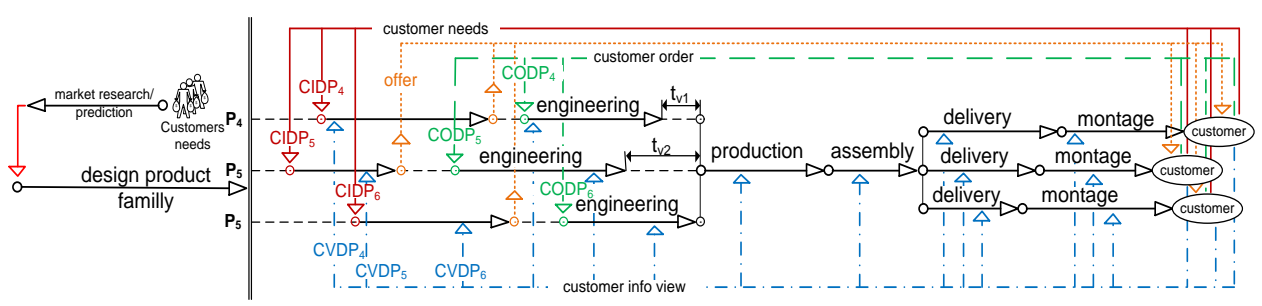

Fig. 8 Customer influence on the production process in the OKP production - small orders case

After that step, one unique work order is created out of several small orders, which resolves the issue of the optimal utilisation of materials and equipment. Production and assembly steps are performed simultaneously for the products from all joined orders, which are followed by a separate delivery and montage (Fig. 8.). The back-end configurators in these OKP companies are expected to support this described scenario, especially regarding the maintenance of the balance between the product effectiveness level and leading time extension because of the fact that the product is put on wait for production (see $\mathrm{t}_{\mathrm{v} 1 \text { and }} \mathrm{t}_{\mathrm{v} 2}$ in Fig. 8).

The OKP approach has been used in industries such as the windows and doors manufacturing industry [11], the sheet metal product design [14], the shoe manufacturing industry [15] and the mobile telephone industry [16].

\section{CONCLUSION}

This paper examines and consider the complexity of the configuration process in the OKP with a dominant topology variation from the point of view of the CIDP position, batch size and complexity of the product configuration process. The paper emphasises several significant issues: the possibility of the product adjustment by the customer OKP production, the complexity of the product configuration process, the possibility of an effective customer integration in that early production phase and the use of the data obtained in the product configuration process for generating the final customised product specifications. The concept of the product complex paradox is particularly stressed, since it refers to the risk of the customer declining the purchase due to too many technical details they encounter during the product configuration as well as to an unavoidable extension of the leading time, which is the consequence of the CIDP position in this type 
of production. The organisation of this type of production is additionally made more elaborate and complicated by the fact that the batch size in the OKP is usually one or several, as well as the common practice of a simultaneous production of several different products. These issues related to the adjusted product configuration and production in the OKP with a dominant topology product variation may be resolved by dividing the configurators into three interconnected parts: front-end, middle-end and back-end configurator. The establishment of a communication channel between the customer, i.e. front-end configurator, and the seller, i.e. middle-end configurator is of utmost importance in order to reduce the product complexity paradox effects. The paper also discusses the positive effect that the automatic reception of the generated data in the front-end and middleend configurators by the back-end configurator has on the reduction of the leading time.

\section{REFERENCES}

[1] Anderson DM. Design for Manufacturability: Optimizing Cost. CIM Press; 1990.

[2] Gitman LJ, Carl DM. The future of business: The essentials. Ohio: South-Western: Mason; 2005.

[3] Rudberg M and JW. Mass customization in terms of the customer order decoupling point. Prod Plan Control 2004; 15:445-58.

[4] Pine BJ. Mass customization: The new frontier in business competition. Boston, MA: Harvard Business School Press; 1993

[5] Gilmore J, Pine BJ. The four faces of mass customization. Harv Bus Rev 1997;75:91-101.

[6] Fogliatto FS, Da Silveira GJC, Borenstein D. The mass customization decade: An updated review of the literature. Int J Prod Econ 2012;138:14-25.

[7] Risdiyono, Koomsap P. Design by customer: Concept and applications. J Intell Manuf 2013;24:295-311.

[8] Wortmann JC. Factory of the Future: Towards an integrated theory for one- of-a-kind production. IFIP Trans B-APPLICATIONS Technol 1992;2:37-74.

[9] Tseng MM, Piller FT. The Customer Centric Enterprise: Advances in Mass Customization and Personalization. New York, NY: Springer; 2003.

[10] Dean PR, Tu YL, Xue D. An information system for one-of-a-kind production. Int J Prod Res 2009;47:1071-87.

[11] Aleksić DS, Janković DS, Stoimenov L V. A case study on the object-oriented framework for modeling product families with the dominant variation of the topology in the one-of-a-kind production. Int J Adv Manuf Technol 2012;59:397-412.

[12] Trentin A, Perin E, Forza C. Sales configurator capabilities to avoid the product variety paradox: Construct development and validation. Comput Ind 2013;64:436-47.

[13] Haug A, Hvam L, Mortensen NH. Definition and evaluation of product configurator development strategies. Comput Ind 2012;63:471-81.

[14] Xie S.Q., Xu X (2006) A STEP-compliant process planning system for sheet metal parts. International Journal of Computer Integrated Manufacturing 19(6):627-638.

[15] Barnett L, Rahimifard S, Newman S (2004) Distributed scheduling to support mass customization in the shoe industry. International Journal of Computer Integrated Manufacturing 17:623-632.

[16] Comstock M, Johansen K, Winroth M (2004) From mass production to mass customization: enabling perspectives from the Swedish mobile telephone industry. Production Planning \& Control 15:362-372 